\title{
Rhodopsin mutations in Chinese patients with retinitis pigmentosa
}

Wai Man Chan, Kwun Yan Yeung, Chi Pui Pang, Larry Baum, Tung Ching Lau, Alvin Kwan Ho Kwok, Dennis Shun Chiu Lam

\begin{abstract}
Aim-To determine the pattern of rhodopsin mutations in Chinese retinitis pigmentosa (RP) patients.

Methods-The rhodopsin gene was examined in $101 \mathrm{RP}$ patients and 190 controls from Hong Kong.

Results-Three coding changes were identified: Pro347Leu, Ala299Ser, and 5211delC. Each protein sequence alteration was found in one patient. Ala299Ser also existed in two controls.

Conclusion-The C-terminal nonsense mutation may cause mis-sorting of rhodopsin protein. The finding of controls with Ala299Ser suggests this is only the third missense alteration reported that does not cause RP. The expected frequency of rhodopsin mutations in RP is $<7 \%(2 / 101=2.0 \%, 95 \%$ confidence interval: $0.2 \%-7.0 \%)$.
\end{abstract}

(Br f Ophthalmol 2001;85:1046-1048)

Mutations in the gene encoding rhodopsin $(R H O)$ lead to retinal degeneration in species from Drosophila to humans. RHO mutations cause autosomal dominant retinitis pigmentosa (ADRP), although a few mutations cause recessive $\mathrm{RP}$ or congenital night blindness, ${ }^{2-6}$ and account for about $25 \%$ of ADRP in Europe $^{78}$ and North America, ${ }^{9-11}$ and less in Japan. ${ }^{12}{ }^{13}$ To investigate the frequency of rhodopsin mutations in Chinese patients with retinitis pigmentosa $(\mathrm{RP})$, and to discover new mutations that may shed more light on rhodopsin's function, we examined the entire coding region and exon splice sites of rhodopsin for sequence changes in $101 \mathrm{RP}$ patients and 190 controls who were all unrelated Hong Kong residents.

\section{Methods}

Unrelated RP patients were identified by fundus examination, assisted by visual field and electrodiagnostic tests at the Prince of Wales Hospital or Hong Kong Eye Hospital in Hong Kong. Control subjects were visitors to

Accepted for publication 12 March 2001

Table 1 Sequence alterations identified in RHO in our study

\begin{tabular}{llllll}
\hline Codon change & Nucleotide change & Exon & $\begin{array}{l}\text { Frequency in } \\
\text { patients }\end{array}$ & $\begin{array}{l}\text { Frequency in } \\
\text { controls }\end{array}$ & References \\
\hline 5' UTR & A269G & 1 & $1 / 101$ & $1 / 190$ & 27,30 \\
Thr62Thr & ACC480ACT & 1 & $1 / 101$ & $0 / 190$ & Novel \\
Leu259Leu & ATC4175ATT & 4 & $1 / 101$ & $0 / 190$ & Novel \\
Ala299Ser & GCC4293TCC & 4 & $1 / 101$ & $2 / 190$ & Novel \\
Intron 4 & G5145A & Intron 4 & $35 / 101$ & $58 / 190$ & 27,31 \\
From 327 & 5211delC & 5 & $1 / 101$ & $0 / 190$ & Novel \\
Thr340Thr & ACG5251ACA & 5 & $1 / 101$ & $0 / 190$ & Novel \\
Pro347Leu & CCG5271CTG & 5 & $1 / 101$ & $0 / 190$ & 32 \\
3' UTR & C5321A & 5 & $11 / 101$ & $20 / 190$ & 27,31 \\
\hline
\end{tabular}

the above hospitals who were over 60 years old and had no major eye disease except cataract. All subjects were ethnic Chinese. Family members of some RP patients also participated. A blood sample was taken after informed consent was given for participation in genetic studies. Approval was given by the ethics committee for human research of the Chinese University of Hong Kong.

We examined the five coding exons and splice sites of $R H O$ in 101 Chinese RP patients and 190 controls from Hong Kong. DNA was extracted from blood, and sequence alterations were detected using polymerase chain reaction (PCR), conformation sensitive gel electrophoresis (CSGE), and DNA sequencing. Sequences were compared with the published human $\mathrm{RHO}$ sequence. ${ }^{14}$

\section{Results}

Of nine nucleotide changes, three alter the protein sequence (Table 1). One was a novel nonsense mutation, $5211 \mathrm{delC}$, predicted to alter the C-terminal sequence by replacing the negatively charged final 22 amino acids containing six phosphorylation sites by a 32 amino acid positively charged sequence with only two Thr. This mutation occurred in one patient, a 53 year old woman whose earliest symptom was night blindness at age 30 . She had a visual acuity of right eye $0.5 / 200$ and left eye 5/200, waxy optic discs, attenuated arterioles, mottled retinal pigment epithelium (RPE), and scattered bone spicule pigmentation. Her younger daughter, who also carried the mutation, was 26 years old with no RP symptoms. However, her RPE was also mottled. Three other relatives were genotypically and phenotypically normal. Two relatives with RP were not available for study.

The commonly reported rhodopsin mutation Pro347Leu was found in one patient, a 55 year old woman. Her earliest symptom was night blindness at the age of 17. She had an acute attack of angle closure glaucoma in her right eye in 1996 which was aborted by laser peripheral iridotomy. Final vision in her right eye dropped to light perception only whereas the left eye held at the level of 20/70. The right optic disc was extremely pale with a cup/disc ratio $(\mathrm{C} / \mathrm{D})$ of 0.8 and optic atrophy subsequent to the acute glaucoma, whereas the left had mild pallor with a $\mathrm{C} / \mathrm{D}$ of 0.2 . Her left visual field was constricted. Fundal examination revealed bone spicule pigments and attenuated vessels. The Pro347Leu mutation was detected in three of her children, aged 33, 28 , and 17. All had night blindness at 17 . They had visual acuity of $20 / 30$, pinkish optic discs, 


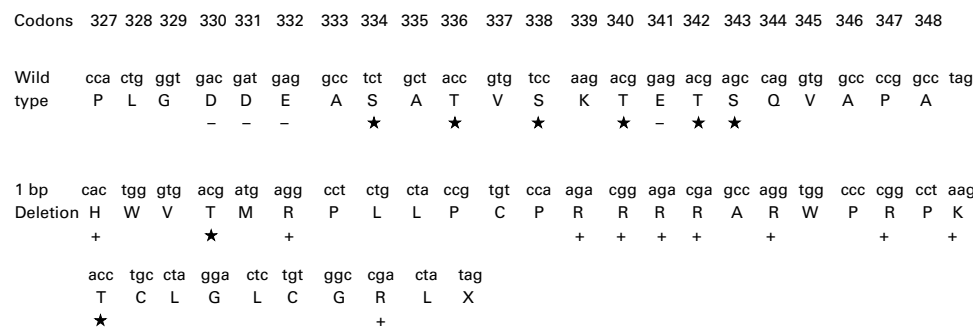

Figure 1 Nucleotide and amino acid sequences of wild type and 5211delC mutant rhodopsin C-terminus. ${ }^{\star}$ Potential phosphorylation sites; +Positively charged residue; - , negatively charged residue.

bone spicule pigments, constricted visual field, and poor scotopic and photopic response in electroretinogram (ERG) in both eyes. The one child without the mutation had no symptoms of RP at age 34 .

The remaining protein sequence alteration, Ala299Ser, was found in one patient. Two control subjects also had Ala299Ser.

\section{Discussion}

The novel nonsense mutation 5211delC should radically alter and extend the carboxyl terminus (Fig 1). Three pathogenic mechanisms are possible:

(1) Loss of two negatively and addition of nine positively charged residues alters the charge of the carboxyl terminus, possibly affecting the structure and function of rhodopsin.

(2) Loss of all six phosphorylatable residues at the C-terminus may prevent activation of arrestin. ${ }^{15-17}$ This may kill the cell by overstimulating the phototransduction pathway, analogous to constant light induced cell death. But ADRP also resulted from a $1 \mathrm{bp}$ deletion closer to the C-terminus, at codon $340,{ }^{18}$ which may not affect phosphorylation since only three of six phosphorylatable residues would be removed.

(3) Loss of the highly conserved C-terminal sequence QVAPA, which controls rhodopsin transport, may misdirect rhodopsin to incorrect cellular locations. ${ }^{19-22}$ Mutations in these amino acids cause severe ADRP. ${ }^{23-25}$

Despite the altered C-terminus, patients did not develop RP early in life. RPE mottling was found at age 26, with onset of night blindness around 30 . Thus, there does not seem to be an additive effect of the above possible pathogenic mechanisms.

The patients with the most commonly reported rhodopsin mutation, Pro347Leu, all had relatively early onset at 17 . This mutation was found in one of 101 index patients, consistent with a frequency of $3.6 \%$ among American ADRP families.

Neutral amino acid substitutions in rhodopsin are rare. So far, only two nonpathogenic missense changes have been reported, Val104Ile ${ }^{26}$ and Phe220Leu. ${ }^{9}$ Sung et $a l^{27}$ screened $R H O$ on 322 chromosomes and found 39 ADRP mutations but no amino acid substitutions unrelated to ADRP. In our study, Ala299Ser was found in a patient and two controls. Ala299 is not well conserved; among 65 vertebrate opsins, only 27 have Ala at this position, while the others all have serine. ${ }^{28}$ Serine can be thought of as a hydroxylated version of alanine. These observations may help to explain why this missense change is well tolerated in humans. However, changing residue 299 to amino acids besides Ser might still cause RP.

RHO mutations represent the most common known cause of RP, occurring in $10 \%$ of cases and over $25 \%$ of ADRP in North America. ${ }^{29}$ There, the most frequent mutation, Pro23His, accounts for one third of rhodopsin induced cases but probably arose in a single ancestor. ${ }^{9}$ It occurs nowhere else. Excluding Pro23His, the proportion of ADRP families with rhodopsin mutations is $16-18 \%,{ }^{79}$ or about $6-7 \%$ of all RP cases, consistent with Japanese studies. ${ }^{13}{ }^{13}$ The proportion of RHO mutations in Chinese RP patients was not previously reported, but the current study measures it as less than $7 \%(2 / 101=2.0 \%, 95 \%$ confidence interval $0.2 \%-7.0 \%$ ). This might be lower than in North America, but more patients must be screened to confirm this trend.

Sponsor: Industrial Support Fund, Li Ka Shing Foundation, Hong Kong.

1 Colley NJ, Cassill JA, Baker EK, et al. Defective intracelluar transport is the molecular basis of rhodopsin-dependent dominant retinal degeneration. Proc Natl Acad Sci USA 1995;92:3070-4.

2 Humphries P, Kenna P, Farrar GJ, et al. On the molecular genetics of retinitis pigmentosa. Science 1992;256:804-8.

3 Rosenfeld PJ, Cowley GS, McGee TL, et al. A null mutation in the rhodopsin gene causes rod photoreceptor dysfunction and autosomal recessive retinitis pigmentosa. Nat tion and autosomal

4 Dryja TP, Berson EL, Rao VR, et al. Heterozygous missense mutation in the rhodopsin gene as a cause of congenital stationary night blindness. Nat Genet 1993;4:280-3.

5 Sieving PA, Richards JE, Bingham EL, et al. Dominant congenital complete nyctalopia and gly90-to-asp rhodopsin mutation. Invest Ophthalmol Vis Sci 1992;33:(Abstract 1397).

6 Al-Jandal N, Farrar GJ, Kiang AS, et al. A novel mutation within the rhodopsin gene (thr94 to ile) causing autosomal dominant congenital stationary night blindness. Hum Mutat 1999;13:75-81

7 Bunge S, Wedemann H, David D, et al. Molecular analysis and genetic mapping of the rhodopsin gene in families with autosomal dominant retinitis pigmentosa. Genomics 1993; 17:230-3.

8 Inglehearn CF, Keen TJ, Bashir R, et al. A completed screen for mutations of the rhodopsin gene in a panel of patients with autosomal dominant retinitis pigmentosa. Hum $\mathrm{Mol}$ Genet 1992;1:41-5.

9 Dryja TP, McEvoy JA, McGee TL, et al. Novel rhodopsin mutations Gly1 14Val and Gln184Pro in dominant retinitis pigmentosa. Invest Ophthalmol Vis Sci2000;41:3124-7.

10 Sung CH, Schneider BG, Agarwal N, et al. Functional heterogeneity of mutant rhodopsins responsible for autosomal dominant retinitis pigmentosa. Proc Natl Acad Sci USA 1991;88:8840-4.

11 Macke JP, Davenport CM, Jacobson SG, et al. Identification of novel rhodopsin mutations responsible for retinitis pigmentosa: implications for the structure and function of rhodopsin. Am ₹ Hum Genet 1993;53:80-9.

12 Shiono T, Hotta Y, Noro M, et al. Clinical features of Japanese family with autosomal dominant retinitis pigmentosa caused by point mutation in codon 347 of rhodopsin gene. caused by point mutation in codo

13 Saga M, Mashima Y, Akeo K, et al. A mutation in codon 181 (Glu $\rightarrow$ Lys) of the rhodopsin gene in a Japanese family. Ophthalmol Genet 1994;15:61-7.

14 Nathans J, Hogness DS. Isolation and nucleotide sequence of the gene encoding human rhodopsin. Proc Natl Acad Sci USA 1984;81:4851-5.

15 Sibley DR, Benovic JL, Caron MG, et al. Regulation of transmembrane signaling by receptor phosphorylation. Cell 1987;48:913-22

16 Ohguro H, Van Hooser JP, Milam AH, et al. Rhodopsin phosphorylation and dephosphorylation in vivo. $7 \mathrm{Biol}$ Chem 1995;270:14259-62.

17 McDowell JH, Robinson PR, Miller RL, et al. Only phosphorylated residues in the carboxyl terminal region of rhodopsin will activate arrestin. Invest Ophthalmol Vis Sci 2000;41:S608.

18 Horn M, Humphries P, Kunisch M, et al. Deletions in exon 5 of the human rhodopsin gene causing a shift in the reading frame and autosomal dominant retinitis pigmentosa. Hum Genet 1992;90:255-7. 
19 Deretic D, Schmerl S, Hargrave PA, et al. Regulation of sorting and post-Golgi trafficking of rhodopsin by its C-terminal sequen QVS(A)PA. Proc Natl Acad Sci USA 1998;95:10620-5.

20 Sung $\mathrm{CH}$, Makino C, Baylor D, et al. A rhodopsin gene mutation responsible for autosomal dominant retinitis pigmentosa results in a protein that is defective in localization to the photoreceptor outer segment. I Neurosci 1994;14:5818-33.

21 Chuang JZ, Sung CH. The cytoplasmic tail of rhodopsin acts as a novel apical sorting signal in polarized MDCK cells. F Cell Biol 1998;142:1245-56.

22 Green ES, Menz MD, LaVail MM, et al. Characterization of rhodopsin mis-sorting and constitutive activation in a transgenic rat model of retinitis pigmentosa. Invest Ophthalmol Vis Sci 2000;41:1546-53.

23 Berson EL, Rosner B, Sandberg MA, et al. Ocular findings in patients with autosomal dominant retinitis pigmentosa in patients with autosomal dominant retinitis pigmentosa 1991;111:614-23.

24 Sandberg MA, Weigel-DiFranco C, Dryja TP, et al. Clinical in dominant retinitis pigmentosa. Invest Ophthalmol Vis Sci in dominant retinitis

25 Macke JP, Hennessey JC, Nathans J, et al. Rhodopsin mutation proline347-to-alanine in a family with autosomal dominant retinitis pigmentosa indicates an important role for proline at position 347. Hum Mol Genet 1995;4:775-6.
26 Macke JP, Davenport CM, Jacobson SG, et al. Identification of novel rhodopsin mutations responsible for retinitis pigmentosa: implications for the structure and function of rhodopsin. Am f Hum Genet 1993;53:80-9.

27 Sung CH, Davenport CM, Hennessey JC, et al. Rhodopsin mutations in autosomal dominant retinitis pigmentosa. Proc Natl Acad Sci USA 1991;88:6481-5.

28 Horn F, Weare J, Beukers MW, et al. GPCRDB: an information system for $\mathrm{G}$ protein-coupled receptors. Nuc Acids Res 1998;26:277-81.

29 Berson EL. Retinitis pigmentosa: Unfolding its mystery. Proc Natl Acad Sci USA 1996;93:4526-8.

30 Dryja TP, Hahn LB, Cowley GS, et al. Mutation spectrum of the rhodopsin gene among patients with autosomal dominant retinitis pigmentosa. Proc Natl Acad Sci USA 1991;88:9370-4.

31 Kawano H, Hotta Y, Fujiki K, et al. A study on the rhodopsin gene in Japanese retinitis pigmentosascreening of mutation by restriction endonucreases and frequencies of DNA polymorphisms. (Abstract) Nippon Ganka Gakkai 1995;99:1151-7.

32 Dryia TP, McGee TL, Hahn LB, et al. Mutations within the rhodopsin gene in patients with autosomal dominant retinitis pigmentosa. $N$ Engl $f$ Med 1990;323: $1302-7$.

\section{Contributors please note:}

Communications from all countries except the UK and Republic of Ireland should be sent to Professor C Hoyt, Editor, British fournal of Ophthalmology, University of California, Department of Ophthalmology, 10 Kirkham Street, K 301, San Francisco, CA 94143-0730, USA (tel: 001415 502-6871; fax: 001415 514-1521).

Manuscripts from the UK and the Republic of Ireland should be sent to Professor Andrew Dick, UK Editor, British fournal of Ophthalmology, Division of Ophthalmology, University of Bristol, Lower Maudlin Street, Bristol BS1 2LX (tel: +44 (0) 0117 929-4496; fax: +44 (0) 117 929-4607). 